CONFERENCIAS

\title{
PROBLEMAS DA POLIMIOSITE
}

\author{
Diogo Furtado *
}

A patologia muscular só nos últimos decênios foi objeto de estudos mais aprofundados, podendo ser considerada, hoje, como dividida em três grandes capitulos, o primeiro dos quais é o da heredopatologia que inclue aquelas afecções condicionadas pelo fator genético e hereditário, isto é, pelas distrofias musculares progressivas.

O segundo é constituido pelas afecções bioquímicas que, embora muitas vêzes também de condicionamento genético, constituem um capítulo novo e autônomo. Estão neste caso as paralisias periódicas: a paralisia periódica familiar é acompanhada de hipocalemia e devida à passagem maciça do potássio para o sarcoplasma muscular, conduzindo a uma despolarização e inibição da descarga nervosa que acarreta a paralisia. Noutros casos, porém, como sucede na adinamia periódica de Gamstorp, o déficit da função muscular não se acompanha de hipocaliemia mas sim de hipercaliemia, sendo idêntico o mecanismo fisiopatológico que leva o potássio, então existente em grande quantidade no sangue, a deslocar-se para dentro do sarcoplasma, conduzindo à inibição da excitabilidade muscular. Várias outras afecções são devidas também a perturbações bioquímicas. É o que sucede, por exemplo, com a doença de McArdle, caracterizada. por crises de fadiga, acompanhadas de dores musculares intensas, de mioglobinúria maciça, de aumento de glicogênio do músculo, coexistindo com baixa do ácido lático; trata-se de doença grave que pode conduzir à morte nas suas crises mais intensas e que é devida à falta de fosrorilases musculares, enzimas indispensáveis para o bom decurso do ciclo de Krebs. Também a miastenia pseudoparalitica, em que o cansaço abole ràpidamente a contração muscular, e a miotonia, caracterizada pelo fenômeno contrário da persistência dessa contração muscular, parcem ser devidas a perturbações bioquímicas, cuja essência ainda não conhecemos.

* Nota da redaçio - Esta conferência foi feita na Clínica Neurológica da Faculdade de Medicina da Universidade de São Paulo, em julho de 1962 pelo Prof. Diogo Furtado, catedrático na Faculdade de Medicina de Lisboa e Diretor do Serviçn de Neurologia dos Hospitais Civis de Lisboa (Portugal). Publicando-a, agora, a r€dação da revista presta uma homenagem a um de seus mais eminentes colaboradores, falecido em julho de 1963. 
Aproveito o ensejo para notar que diversas vêzes falarei de mioglobinúria, de creatinúria, de excreção exagerada de fermentos. Estas alterações que foram consideradas como especificas de certas afecções musculares são totalmente inespecificas e devidas à destruição de massas musculares mais ou menos consideráveis. A mioglobina, globulina contida no sarcoplasma do músculo, é eliminada em muitas circunstâncias da patologia muscular e essa eliminação nada tem de específico. Da mesma forma a creatina, que normalmente não surge na urina visto ser transformada ao nível do músculo em creatinina, por sua vez então eliminada, pode aparecєr também em grandes quantidades sempre que haja destruições musculares intensas. Também a excreção exagerada de aldolase ou de transaminase glutâminoxalacética ou pirúvica tem significado idêntico, não constituindo achado específico para qualquer doença muscular.

O tercveiro grupo de afecções da patologia muscular é constituido pelas miosites, isto é, doenças em que há inflamação, específica ou não.

Referir-me-ei, ràpidamente, às miosites específicas, processos inflamatórios difusos produzidos por agentes conhecidos. Podem ser devidas a bactérias, como é o caso da miosite que surge nos estados sépticos com formação de focos inflamatórios múltiplos ao nível dos músculos, ou na gangrena gasosa, na qual há destruição difusa das fibras musculares, com formação de gaz. Outros agentes específicos são capazes de produzir miosite; é o que sucede na sífilis, na tuberculose e nas leptospiroses. Também a febre tifóide, na era anterior aos antibióticos, determinava com certa freqüência uma miosite dos músculos abdominais que levava a verdadeiras destruições necróticas, acompanhadas de degenerescência céria de Zenker, em geral muito intensa. $\mathrm{Na}$ actinomicose pode ocorrer miosite mais ou menos extensa. Diversos parasitas são suscetiveis também de provocar miosites: na triquinose a localização muscular é capital; na cisticercose também os parasitas podem localizar-se nos músculos; também o toxoplasma pode atacar os músculos, da mesma forma como o equinococo é suscetível de provocar quistos hidáticos intramusculares. O Schizotripanum Cruzi que produz a doença de Chagas, além da estrumite característica da afecção, pode localizar-se nos músculos e determinar miosite. As miosites específicas podem também ser devidas a vírus. Diversos tipos de miosite aguda, tais como a mialgia epidêmica e a doença de Bornholm, parecem ser provocadas por vírus próximos do vírus poliomielítico. Uma afecção de extrema gravidade, muitas vêzes mortal, que é a rabdomiolise paroxística recorrente na qual grande número de músculos entra em necrose maciça, parece igualmente ser devida à interferência de vírus.

As miosites não específicas têm tido na patologia a designação de polimiosite e dermatomiosite. Foi Wagner, em 1863, o primeiro que descreveu uma afecção inflamatória difusa dos músculos acompanhada de lesões da pele. Hepp, em 1887, confirmou esta descrição e, assim, surgiu a dermatomiosite. Em 1890, Unverricht relatou casos em que o processo inflamatório se limitava aos músculos, não atingindo a pele, e designou-os de polimicsite. Estas formas de polimiosites difusas, não específicas, passaram quase despercebidas na literatura médica. Os dermatologistas tomaram à 
sua conta a dermatomiosite e diagnosticavam-na com relativa freqüência, mas sempre que não existiam lesões cutâneas a doença passava no geral despercebida.

Em 1945, com F. Alvim, descrevemos uma afecção muscular inflamatória com atrofia das cinturas proximais, sobretudo da cintura escapular, interessando também outro músculos de maneira aberrante, como, por exemplo, os músculos oculares, e que, ao exame histopatológico, apresentava lesões de polimiosite. Entretanto, também esta forma de polimiosite a que chamamos pseudomiopática passou mais ou menos despercebida e, na realidade, só a partir de 1945, uma série de trabalhos de Eaton, Walton, Denny-Brown, Shy, MacEachern e R. Garcin trouxeram ao conhecimento geral a importância da polimiosite.

Antes de entrar no estudo dos limites nosológicos e clínicos das polimiosites interessa saber como se manifesta, ao nivel do músculo, a inflamação.

O músculo é uma unidade funcional complexa, constituida pelas células musculares, pelo tecido intersticial conjuntivo-vascular e pelo aparelho mioneural que estabelece relação com o sistema nervoso. A célula muscular ou miócito é alongada, constituindo a fibra muscular, multinucleada, tendo os seus núcleos na periferia, sob uma membrana que a limita (sarcolema); os miócitos, com vários centímetros de comprimento, são caracterizados pela presença de fibrilas contidas numa substância intersticial (sarcoplasma). A inflamaçāo atinge principalmente o tecido intersticial e os miócitos.

Ao nivel do tecido intersticial e das terminações vasculares, a inflamação manifesta-se pelo aparecimento de células redondas (linfócitos, células plasmáticas e muitas vêzes histiócitos) que podem infiltrar difusamente todo o espaço entre as fibras, mas que podem também constituir nódulos infiltrativos, sobretudo em tôrno dos vasos. Esta reação do tecido intersticial que constitui, para alguns autores, elemento indispensável para definir a existência de inflamaçāo no músculo, evolui depois no sentido de um aumento de tecido conjuntivo com fibrose, colagenose $e$, por vêzes, mesmo com infiltraçōes gordas, por lipócitos.

Ao nivel dos miócitos, das fibras musculares, encontram-se em geral também alterações graves. Para alguns autores são estas alterações dos miócitos que definiriam o caráter inflamatório do processo patológico. As alteraçōes dos miócitos sāo de intensidade e extensão variável, mas por vêzes extremamente marcadas, consistindo numa degenerescência com apariçāo de vácuolos, degenerescência granulosa constituida por condensaçāo das proteinas do sarcoplasma e, nos estados mais avançados, degenerescência céria, perturbaçōes graves da colorabilidade, fragmentaçāo e, por fim, necrose. A perda da estriação constitui quase sempre um fenomeno que se observa logo no início da inflamação, da mesma forma como alterações ligeiras da colorabilidade dos miócitos sāo também manifestações iniciais da sua alteraçāo. Os núcleos sofrem graves perturbações, no decurso do processo inflamatório. O número de núcleos do sarcolema aumenta consideràvelmente; além disso, êstes núcleos apresentam fenômenos degenerativos, mostrando-se muitas vêzes vesiculosos, de grande volume, finamente granulosos ou hipercromáticos; fato muito caracteristico é os núcleos migram para o interior da fibra muscular dispondo-se umas vêzes em rosários, acumulando-se outras em massas nucleares.

Além dêstes fenômenos puramente degenerativos que traduzem a alteração do miócito, é possivel encontrar fenômenos de caráter regenerativo que manifestam-se de várias formas. A própria alteração dos núcleos do sarcolema provàvelmente jả é um fenômeno regenerativo; sua proliferação, sua migração central e seu aumento de volume têm provàvelmente êsse significado. Muitas vêzes os núcleos do sarcolema aglomeram-se em massas nucleares situadas em geral nas extremidades 
necrosadas dos miócitos, sendo êsse fenômeno encarado também como tentativa de regeneraçāo. O aparecimento de basofilia do sarcoplasma e de pequenas fibras basófilas neoformadas tem, para os histopatologistas modernos, o mesmo significado de manifestação regenerativa do músculo. ültimamente também se indica, como tendo o significado de um esforço de regeneração do miócito, o aumento de ácido desoxiribonuclêico no seu sarcoplasma.

A lesão inflamatória do músculo assim definida pode variar muito de intenidade. Em alguns casos a lesāo predomina no tecido intersticial, em outros é mais intensa nos miócitos tendo certos autores procurado ver correspondências clínicas diversas nesta diversidade de tipos histológicos. Assim, para Antonetti e Scopinari e seus colaboradores, a miosite intersticial representaria uma forma anátomo-clinica integrável no grupo das colagenoses, ao passo que a miosite parenquimatosa primária em que a lesão do miócito estaria em causa seria a verdadeira miosite primitiva. Entretanto, há que salientar que na imensa maioria dos casos existem lesōes de ambos os tipos, a inflamação intersticial acompanhando-se de lesões degenerativas das fibras.

Não será também demais acentuar que se não pode ainda estabelecer uma relação entre os quadros clinicos e as lesões encontradas. Mesmo em casos de miosites acompanhando as doenças do colágeno é possível encontrar, como sucede no lupus eritematoso, lesões mais importantes dos miócitos do que do tecido intersticial.

A sintomatologia da polimiosite aguda é inicialmente constituída pela dor e pela sensibilidade à pressão do músculos atingidos. Êstes, à palpação, apresentam muitas vêzes consistência anormal, dando a impressão de edemaciados ou de exageradamente flácidos. Certos músculos particularmente dolorosos podem apresentar contracturas e, mesmo, rigidez. Ao fim de algum tempo, ocorre atrofia que atinge principalmente os grupos musculares mais afetados pelo processo inflamatório. A distribuição preferencial das atrofias consecutivas ao processo miositico é proximal, tal como ocorre também nas distrofias miopáticas.

As atrofias da polimiosite têm, porém, a particularidade de atingirem outros músculos que habitualmente não são interessados nos processos distróficos. Na realidade, a polimiosite pode atingir todos os músculos do corpo e daí o variado quadro clínico. É o que sucede, por exemplo, com a participação dos músculos da nuca, que pode ser muito intensa impedindo a sustentação da cabeça, e com a participação dos músculos oculares, que não é rara. Também a musculatura faringea pode ser interessada dificultando a deglutição e a fonação. Não é raro que os doentes com polimiosite tenham alterações intensas da articulação da palavra e da voz. Os músculos respiratórios podem participar no processo, determinando paralisia respiratória e morte por asfixia.

Outra das caracteristicas da musculatura polimiosítica é a possibilidade do aparecimento de reações do tipo miastênico ou miotônico. Em geral esta miastenia tem distribuição irregular, sendo por vêzes limitada apenas a um grupo muscular. Também a sua resposta aos medicamentos antimias. tênicos é irregular, menos nítida e clara do que a resposta dos músculos com miastenia pseudoparalítica. A miotonia pode encontrar-se clìnicamente mas pode também apenas se apreciar quando do exame eletromiográfico.

O eletromiograma apresenta, na polimiosite, características particulares. Em repouso, não são raros os potenciais de fibrilação, isto é, indícios de 
denervação tal como aparecem nas lesōes do neurônio periférico e ao contrário do que sucede nas distrofias musculares. Também é freqüente, na polimiosite, ocorrer reação miotônica manifestada, quando a agulha é inserida no músculo, pelo ruído característico da salva em "bombardeiro mergulhante". Durante o esforço muscular os potenciais encontrados não divergem dos que são encontrados na distrofia muscular progressiva, isto é, são potenciais de baixa voltagem, de aspecto irregular, muitas vêzes polifásicos, policíclicos, com morfologia diferente da normal e freqüentemente de curta duração. Êste traçado interferencial constituído por potenciais de baixa voltagem, numerosos mas polifásicos, é encontrável tanto na polimiosite como nas distrofias musculares progressivas; nestas últimas, porém, a falta dos potenciais de fibrilação e a falta de reação miotônica permitem distinção eletromiográfica. Além disso, estudos modernos tendem a mostrar que o número de fases é maior na distrofia muscular progressiva do que nas miosites, sendo portanto os potenciais mais polifásicos e o quociente (tempo de duração/número de fases) muito menor. Também a curva de intensidadeduração, empregada hoje por muitos eletrologistas, permite fazer distinção entre as polimiosite e as distrofias musculares progressivas.

Limites da polimiosite aguda e subaguda - E dificil o diagnóstico diferencial entre a polimiosite e a dermatomiosite. Já fizemos menção às íntimas relações destas duas afecções, que não representam mais do que uma única doença com dois aspectos clínicos consoante predominem, ou não, as lesões cutâneas.

O quadro clínico geral da dermatomiosite é idêntico ao da polimiosite aguda; há importante repercussão geral constituída por hipertermia, incremento da velocidade de sedimentação, mau estado geral, evoluindo muitas vêzes para a morte. As pesquisas de laboratório, no que se refere à patologia muscular, mostram exagerada quantidade de creatina na urina, aumento das transaminases e da aldolase, por vêzes excreção maciça de potássio com hipocaliemia e, ainda às vêzes, o aparecimento de mioglobina na urina. Todos êstes dados resultam do processo maciço de detruição muscular.

A dermatomiosite é a forma de polimiosite que se acompanha de lesões cutâneas; entretanto, a análise dos casos mais recentes de polimiosite leva a crer que em quase todas as formas agudas desta doença existem lesões cutâneas. Podemos, pois, dizer que entre polimiosite aguda e dermatomiosite não há pràticamente diferenciação. As lesões cutâneas são extremamente freqüentes nas formas agudas de polimiosite e quando elas predominam a doença pode legitimamente tomar o nome de dermatomiosite; na sua essência porém trata-se do mesmo processo patológico.

Queremos aqui fazer uma referência às relações da dermatomiosite com as neoplasias malignas. Num número elevado de casos de dermatomiosite, número que, consoante as estatísticas vai de 6 a $40 \%$, existem simultâneamente neoplasias malignas, sobretudo carcinomas do pulmão, do seio, do estômago, do tubo digestivo ou dos órgãos genitais. Não há ainda explicação plausivel para esta relação da dermatomiosite com as neoplasias malignas. 
Outra limitação que pretendemos fazer para a polimiosite é com as neuropatias periféricas. A associação duma neuropatia periférica com a polimiosite é relatada por numerosos autores; a chamada neuromiosite ou neurodermatomiosite de Senator não é mais do que a tentativa de individualizar numa entidade mórbida êste fato que referimos. Não são raros os casos em que à polimiosite se associam manifetações da participação dos nervos periféricos; a sintomatologia da neuropatia periférica (abolição dos reflexos, paralisia flácida distal com amiotrofias e alterações da sensibilidade de distribuição também distal) vai-se a pouco e pouco enxertando sôbre o quadro de polimiosite, desvirtuando o aspecto clínico desta e dificultando o diagnóstico. Numa fase mais adiantada só a biopsia dos msculos proximais. mostrando a existência dum processo miositico, pode fazer descortinar êste no meio do quadro clínico muito mais espetacular, da neuropatia periférica totalmente desenvolvida.

Ocupar-nos-emos, agora, dos imprecisos limites nosológicos, entre as polimiosites e as doenças do colágeno. Desde Klemperer agrupa-se sob a designação de colagenoses certo número de afeç̃ões que muitos autores atribuem a patogenia alérgica e que mantêm com a polimiosite relações intimas, comprovadas por duas circunstâncias fundamentais: a primeira é a de que em todas as doenças do colágeno há lesões miositicas mais ou menos importantes; a segunda é de que na polimiosite ocorrem alterações do tecido intersticial muito semelhantes às que caracterizam as doenças do colágeno.

Com efeito, existem nas colagenoses lesões musculares de variável importância mas bastante regulares. Assim, no lupus eritematoso é freqüente o encontro de focos inflamatórios intramusculares; recentemente diversos autores, entre êles Pearson e Rose, insistiram sôbre a existência de lesões vacuolares dos miócitos no decurso do lupus eritematoso. Na periarterite nodosa, as lesões arteriais que atingem mais ou menos todo o organismo, têm preferência bem conhecida pelos músculos, nos quais ocorrem infiltrações intersticiais importantes, focos de perivascularite circundando as artérias atingidas pela panarterite e, muitas vêzes, lesões de isquemia e infartos do tecido muscular, com necrose e eliminação; a par dêste processo miositico, que muitas vêzes passa despercebido, o quadro é freqüentemente dominado por uma neuropatia periférica na qual a participação dos músculos é também importante. $\mathrm{Na}$ esclerodermia também as lesões musculares são importantes. Nas formas crônicas a esclerose cutânea propaga-se aos tecidos subcutâneos e aos músculos e vai até ao plano ósseo; nesses casos a fibrose do músculo e a eliminação dos miócitos ocorre com regularidade. Mas mesmo nas formas mais agudas da esclerodermia e nas doenças afins, como ocorre no escleroderma de Bushke, por exemplo, é freqüente o encontro de lesões musculares de tipo inflamatório com alterações intersticiais mais ou menos importantes, alterações vasculares e lesões graves dos miócitos. $\mathrm{Na}$ própria artrite reumatóide sistêmica são encontradas lesões musculares do tipo da polimiosite; não é raro encontrar, na proximidade dos artículos atingidos pela artrite reumatóide, lesões inflamatórias dos músculos. 
Assim podemos dizer que em todos ou quase todos os casos de doença do colágeno podem ser encontradas lesões miosíticas mais ou menos acentuadas. A reciproca também é verdadeira. Na polimiosite e na dermatomiosite há, com grande freqüência, lesões similares às da colagenose. À participação do colágeno intersticial no processo miosítico já nos referimos, bem como às lesões arteriais. Estas são, em alguns casos de polimiosite, extremamente acentuadas, com alterações da parede, infiltrações por células redondas e focos perivasculares, muitas vêzes indistinguiveis dos da panarterite nodosa. Também, como dissemos atrás, na polimiosite e na dermatomiosite, sobretudo nas formas agudas, as lesões cutâneas são freqüentes e fazem parte, por assim dizer, do quadro clínico das polimiosites agudas. Outra particularidade que aproxima as polimiosites das doenças do colágeno é a possibilidade de encontrar, nas primeiras, as células LE características do lupus eritematoso e de outras colagenoses. E, por último, a existência de lesões articulares aproxima as polimiosites da artrite reumatóide; essa presença de lesões articulares não é rara e as lesões referidas são clìnicamente similares às da artrite reumatóide.

Também os dados laboratoriais aproximam os dois grupos de afecções. Com efeito, na polimiosite tem sido obtidos resultados característicos da artrite reumatóide, tais como a existência de proteina $\mathrm{C}$ reativa, a positividade do teste de fixação do latex, a aglutinação das células sensibilizadas do carneiro. Também na polimiosite pode ocorrer a deposição importante de gama-globulina que se verifica nas artrites reumatóides; pela técnica dos anticorpos fluorescentes consegue-se verificar êste depósito de globulinas anormais ao nível das lesões de polimiosite.

Em face dêstes dados que aproximam os dois grupos de afecções ocorreria perguntar se a polimiosite não será também uma colagenose. Como é sabido, estas doenças, sobretudo o lupus eritematoso, são encaradas atualmente como doenças por autoclasia. Admite-se que se dá a fixação duma gama-globulina anormal no ácido desoxiribonuclêico contido no núcleo das células; esta deposição nas células sanguíneas daria lugar ao fenômeno de Hargrave, da mesma maneira como a deposição ao nivel dos tecidos levaria à formação de iso-anticorpos responsáveis pelos fenômenos morfológicos anormais. As doenças do colágeno, em particular o lupus eritematoso, seriam doenças por auto-agressão. No que refere à polimiosite é muito provável que ela seja a expressão muscular do mesmo processo patológico reativo que se exprime pela colagenose. As lesões encontradas e o decurso da afecção levam a crer que polimiosite e doenças do colágeno constituam dois grupos entre os quais a transição se faz insensivelmente e cuja patogenia não estará longe de ser a mesma.

Quero ainda fazer uma referência aos limites entre a polimiosite e as miosites agudas, em geral devidas a causas específicas. Entretanto não é raro que um surto de miosite aguda - doença de Bornholm, doença de McArdle ou outra - possa dar a um quadro mais ou meno prolongado ou até crônico de polimiosite. É claro que as lesões se aproximarão muito das da polimiosite primitiva, mostrando que o músculo tem número limitado de formas de reação. 
Entretanto, a existência de etiologias definidas para as formas de miosite aguda permite em geral separá-las da polimiosite não específica mesmo quando esta tome um curso agudo. Para a maior parte das miosites agudas, a restante sintomatologia que acompanha a afeçãa e os dados laboratoriais que lhe são característicos, permitirão estabelecer uma distinção.

Limites da polimiosite crônica - As formas crônicas de polimiosite apresentam, em geral, dois característicos fundamentais: o primeiro é a ausência das lesões cutâneas que ocorrem nas polimiosites agudas e das dermatomiosites; o segundo é a menor intensidade dos fenômenos inflamatórios e, em contrapartida, a maior intensidade das atrofias. $O$ que em geral é mais típico da polimiosite crônica é o quadro de amiotrofia mais ou menos difuso pelo qual a doença se manifesta. Esta circunstância leva-nos a falar, em primeiro lugar, dos limites entre a polimiosite e as distrofias musculares progressivas.

As distrofias musculares progressivas constituem um grupo de afecções de caráter hereditário, sendo admitidas três formas principais. A primeira, a forma infantil, corresponde ao antigo tipo pseudo-hipertrófico de DuchenneGriesinger em que a hereditariedade é recessiva e ligada ao sexo, a afecção aparecendo quase exclusivamente em individuos do sexo masculino. A segunda é a forma fácio-escápulo-humeral, correspondente ao tipo LandouzyDéjerine, na qual o aparecimento é juvenil e as atrofias são, muitas vêzes, limitadas apenas à face e à cintura escapular; esta forma transmite-se como dominante, autossômica mas com penetração incompleta, o que explica a variabilidade existente em certas famílias. A terceira é a forma atrófica das cinturas, correspondendo aos antigos tipos de Erb e Leyden-Moebius, na qual o aparecimento tardio juvenil é também característico; a doença se limita às cinturas escapular e pélvica, transmitindo-se de modo dominante ou recessivo, autossômico e também com penetração incompleta. Em tôdas estas formas de distrofia muscular, nem a histopatologia nem o quadro clínico ou a eletromiografia permitem sempre estabelecer uma distinção nítida com as polimiosites.

Na forma que, em 1945, descrevemos com F. Alvim, a polimiosite de forma pseudomiopática, procuramos pôr em relêvo esta circunstância. $\quad \hat{E}$ que nas polimiosites crônicas a amiotrofia distribui-se muitas vêzes às cinturas proximais, tomando o aspecto clínico de uma distrofia escápulo-humeral ou pélvica tardia. Por outro lado, no quadro histopatológico, se as grandes reações inflamatórias parenquimatosas ou intersticiais são características da miosite, a verdade é que alguns casos de distrofia muscular progressiva apreentam também infiltrações bastante intensas de células redondas.

Nos casos de distrofia muscular, quando a destruição dos miócitos é muito intensa, pode ser encontrado grande número de núcleos do sarcolema e reação fagocitária intersticial tão intensa que pode levar à confusão com o quadro duma polimiosite; a distinção histopatológica entre uma e outra afecção, portanto, nem sempre é fácil. Por outro lado, também o eletromiograma não permite distinção segura; com efeito, o eletromiograma da distrofia 
muscular, durante o esforço, é perfeitamente idêntico ao da polimiosite, apresentando um traçado interferencial de baixa voltagem com unidades motoras de aspecto policíclico e irregular; apenas o número de ciclos e o quociente fásico permitem talvez uma diferenciação. No repouso, pode haver distinção quando existam potenciais de fibrilação ou salvas de bombardeiros mergulhantes como prova de uma reação miotônica, elementos indicadores de polimiosite.

$\mathrm{Na}$ realidade, o que permite estabelecer o diagnóstico de polimiosite em face da possibilidade de distrofia muscular progressiva é o conjunto do quadro. No quadro clínico, além das atrofias proximais, existem, na polimiosite, muitas vêzes participaçōes de músculos que não intervêm nos processos distróficos; é o caso dos músculos oculares, faríngeos e respiratórios. A existência de dores à pressão e de contratura precoces são muito mais características da polimiosite do que da distrofia muscular progressiva. Outro elemento importante é a falta de incidência familiar na polimiosite, contràriamente ao que se encontra com regularidade bastante grande nas distrofias musculares progressivas; é certo que existem casos esporádicos de distrofia muscular progressiva, mas a verdade é que na maior parte das observações é possivel obter indicação anamnésica de doença hereditária. Também a evolução é importante para o diagnóstico; ao passo que a evolução da distrofia muscular progressiva se faz com relativa rapidez para uma imobilidade total com atrofia que nāo permite qualquer espécie de movimento, na polimiosite, sobretudo nas formas crônicas, a evolução é lenta e passível de melhoras.

Entretanto a distinção entre as formas crônicas de polimiosite e as distrofias musculares progressivas constitui um dos pontos mais controvertidos da atual patologia muscular. Sem chegar ao exagero de Donebel que afirma que $40 \%$ das miopatias tardias não são distrofias musculares mas sim polimiosites, continuamos convencidos de que certo número de casos diagnosticados como distrofias musculares são, na realidade, polimiosites crônicas.

Outra limitação que pretendemos fazer é entre a polimiosite e a chamada miopatia ocular. Desde fins do século passado Moebius descreveu uma oftalmoplegia crônica progressiva caracterizada pelo aparecimento de paralisias oculares limitadas mas progressivas e atribuída, por vários tratadistas, a lesões centrais sediadas no tronco cerebral; dai o nome de oftalmoplegia nuclear progressiva. Entretanto a casuística publicada não era convincente. Os diversos casos de oftalmoplegia nuclear progressiva que chegaram até ao exame necrópsico, não mostravam lesões dos núcleos motores oculares em grau convincente; na maioria mesmo não existiam quaisquer lesōes. Por isso Fuchs, há muitos anos, tinha aventado que a oftalmoplegia nuclear progressiva fosse, na realidade, uma doença muscular. Mais tarde Kiloh e Nevin, estudando biopsias de músculos oculares em alguns dêsses doentes, verificaram a existência de lesões importantes que caracterizariam uma forma particular de distrofia muscular a que chamaram miopatia ocular. A êsses estudos seguiram-se os relatos de outras observações que levaram a admitir a patogenia miógena das oftalmoplegias crônicas progressivas. Nós mesmos adotamos, em 1952, êsse ponto de vista. Entretanto, revendo os nossos casos, 
inclinamo-nos hoje a admitir que essa forma localizada de distrofia muscular possa ser também uma polimiosite; as lesões musculares, caracterizadas sobretudo por grande aumento dos núcleos do sarcolema e pela infiltração de células redondas, permitem a dúvida sôbre se realmente se trata duma distrofia muscular ou duma polimiosite.

Tem grande interêsse e nos últimos anos tem sido largamente discutida a limitação entre distrofia muscular da menopausa e polimiosite. Esta distrofia muscular da menopausa foi descrita por Nevin. e considerada como afecção distrófica esporádica. Já tive ocasião de dizer que existem casos esporádicos de distrofias musculares mas que tais casos são excepcionais e que existem também casos nìtidamente tardios das mesmas distrofias, igualmente muito raros. O que é hoje relativamente freqüente é a circunstância de que uma distrofia muscular de aparecimento juvenil relativamente benigna, possa passar despercebida, ir-se manifestando lentamente e só atingir o seu pleno desenvolvimento muito mais tarde. Essa circunstância é hoje muito mais freqüente porque as complicações que habitualmente determinava o óbito de pacientes com distrofias musculares, sobretudo as respiratórias, são curáveis pela terapêutica antibiótica, disso resultando que tais pacientes vivem muito mais, não sendo poucos os pacientes com distrofias rotuladas como formas juvenis que ultrapassam os quarenta anos de idade.

Os livros dos diversos autores que recolheram grandes casuisticas de miopáticos, sobretudo o de Becker que inclui mais de 4.000 miopáticos existentes na Alemanha e o de Davidenkow resumindo a casuística russa, mostram que as formas tardias de distrofia muscular progressiva existem realmente mas são excepcionais; o que é mais freqüente é a evolução prolongada e a longa sobrevivência dos pacientes com distrofias musculares juvenis.

Contràriamente à interpretação aos casos descritos inicialmente por Nevin, os que foram publicados ulteriormente por Shy e Eachen e por muitos outros autores, não parecem corresponder a uma distrofia muscular da menopausa, mas sim a um processo polimiosítico. $O$ aparecimento da mol;stia em periodo próximo à menopausa, a localização pélvica, a evolução rápida das atrofias, o traçado eletromiográfico e, sobretudo, as lesões histopatológicas levam à conclusão de que não se trata de distrofia muscular tardia mas sim duma forma autônoma de polimiosite. Em um caso nosso as lesões de tipo miosítico, quer dos miócitos quer do tecido intersticial, eram de tal modo manifestas que não permitiam pôr em dúvida o diagnóstico de polimiosite. Daí a designação que damos atualmente a esta forma de afecção muscular, de polimiosite pseudo-miopática tardia. Para nós a forma descrita por Nevin não é mais do que um caso particular da polimiosite pseudomiopática aparecida tardiamente, na altura do climatério, mas não específica dêste, visto que é possivel também o seu aparecimento em homens, como no caso descrito por Garcin.

Referìr-me-ei, ainda, à limitação entre a polimiosite e a miosite fibrosa ou, segundo a nossa designação, polimiosite esclerosante. A miosite fibrosa, descrita por Janicke em 1895, é caracterizada por uma transformação do tecido muscular em tecido conjuntivo, manifestando-se clìnicamente por dores, 
rigidez muscular e, depois, fixidez e impossibilidade de contração do músculos, à medida que se vai dando sua transformação fibrosa progressiva; pode haver uma fase inicial de hipertrofia, à qual se segue atrofia, reduzindo os músculos a cordões fibrosos. Essa afeç̧ão, na opinião da maioria dos autores antigos, seria resultante duma transformação metaplásica dos miócitos em fibrócitos; o músculo seria, ou invadido por um tecido fibroso de origem desconhecida ou sede dum processo de metaplasia traduzido pela transformação das fibras musculares em tecido fibroso.

Observação que apresentamos recentemente na Sociedade Francesa de Neurologia permitiu-nos mostrar que, também aqui, se trata provàvelmente dum processo miosítico. No nosso caso, como de resto noutros casos anteriores, foi possivel encontrar zona onde os focos inflamatórios eram manifestos e, por vêzes, muito intensos; a par dessas zonas havia outras onde fibras musculares mais ou menos conservadas alternavam com outras com graves fenômenos de degenerescência e regeneração. Nas zonas onde o processo fibrótico era mais manifesto e acentuado havia transformação conjuntiva do músculo, com aspectos sarcomatóides; conduzindo a um estado final em que a conetivação do músculo atingia um aspecto quase de tendão; entretanto, mesmo nas zonas onde as fibras conjuntivas constituiam a maior parte da estrutura muscular, era ainda possivel encontrar algumas fibras musculares isoladas com alteraçōes mais ou menos intensas. A nossa e observações mais recentes de outros autores levam à conclusão que a miosite fibrosa é, na realidade, o têrmo final de um processo inflamatório que, por circuntâncias que desconhecemos, têm particular tendência à evolução para a colagenose e fibrose rápida e definitiva.

Também merece referência a limitação da polimiosite com a miosite ossificante, afecção caracterizada pela transformação osteogenética dos músculos e que se acompanha de certas malformações de natureza congênita (cifoescoliose, anomalias dos dedos grandes dos pés) que podem levar a crer tratar-se de doença de condicionamento genético. Entretanto trabalhos recentes, sobretudo de autores italianos, levam à convição de que existe uma fase inflamatória miosítica na evolução do músculo para a transformação óssea. Não tivemos ensejo de observar qualquer caso desta doença; é nossa conviç̧ão, entretanto, de que na miosite ossificante, como na miosite fibrosa, existe inicialmente um processo inflamatório sôbre o qual, talvez por deficiência enzimática se enxerta a metaplasia óssea.

Uma referência ainda à miopatia paracancerosa. Fizemos já referência à freqüente coexistência, a da dermatomiosite com neoplasias malignas, sozretudo carcinomas. Entretanto em muitos tumores malignos se tem verifi- 
cado também a existência de alterações musculares que muitas vêzes passam despercebidas no quadro geral da caquexia. Heathfield e Williams, individualizaram esta forma de miopatia a que chamaram pseudomiastenia dada a freqüência com que nela se encontra a reação miastênica associada às atrofias musculares. O exame histológico, porém, mostra que as alteraçōes de musculos situados à distância do tumor maligno não são raras; estas alterações consistem em atrofias extensas das fibras, perda da estriação, anomalias de colorabilidade, aumento dos núcleos do sarcolema e, por vêzes, imagens regenerativas. Numa investigação que fizemos com Neves da Silva encontramos, com certa freqüência, alterações dêste tipo em neoplasias generalizadas. A patogenia desta miopatia paracancerosa que, como as neuropatias dêsse tipo, não dependem da ação direta ou tóxica da neoplasia, é desconhecida, como o é a sua relação com a polimiosite.

Terminarei fazendo menção, embora rápida, a uma investigação que há meses trazemos em curso e que diz respeito à provocação experimental de uma forma de distrofia muscular com grandes afinidades com a polimiosite humana. Diversos autores verificaram, no homem, que a injeção de corticosteróides em grandes doses e administração prolongada produz amiotrofia mais ou menos acentuada; encontrada para diversos corticosteróides, esta amiotrofia tem sido verificada ùltimamente sobretudo quando é usada a triancinolona.

Partindo dêste conhecimento, intentaram Ellis e colaboradores a provocação experimental destas lesões e encontraram realmente, no coelho, acentuadas lesões histopatológicas dos músculos. Há meses, empreendemos o estudo desta afecção muscular experimental, preparando diversos lotes de coelhos injetando-lhes diferentes tipos de corticosteróides. Ùltimamente, pela riqueza das lesões provocadas, usamos exclusivamente a dexametazona, verificando, nos animais, a existência de um processo atrófico inflamatório dos músculos que muito se aproxima da polimiosite humana; encontramos graves alterações degenerativas das fibras, iniciadas por perda da estriação e alteração da colorabilidade, seguidas de degenerescência granulosa ou vacuolar, necrose dos miócitos com fagocitose e, por vêzes, imagens regenerativas. Em certos animais, a proliferação intersticial de células redondas era extremamente intensa, originando aspectos idênticos aos das miosites das colagenoses. As lesões vasculares, pelo contrário, eram insignificantes. Esta miopatia experimental atinge todos os músculos do corpo, mas é mais intensa na musculatura proximal; encontramo-la igualmente na musculatura cefálica (músculos mastigadores e oculares). Atualmente procuramos esclarecer a influência que sôbre a gênese desta polimiosite experimental tem as glân- 
dulas de secreção interna, repetindo os ensaios em animais prèviamente tiroidectomizados e suprarrenalectomizados.

Assim, a polimiosite é uma forma inespecífica de reação difusa do músculo, que tanto pode resultar da ação de uma causa flogógema como de um fator alérgico ou de um violento abalo endocrínico que repercuta sôbre a musculatura. As escassas possibilidades de reação desta última fornecem as mesmas imagens inespecíficas para múltiplas causas. A circunstância de podermos reproduzir experimentalmente essas alterações e estudar, assim, as causas que as agrảvam ou atenuam, não poderá deixar de contribuir para melhorar nossos conhecimentos quanto à fisiopatologia da afecção. 